\title{
Potentiation of the uterus-relaxing effects of $\beta$-adrenergic agonists with nifedipine: studies on rats and the human myometrium
}

\author{
JUDIT HAJAGOS-TÓTH ${ }^{1}$, ZSOLT KORMÁNYOS ${ }^{2}$, GEORGE FALKAY ${ }^{1}$, ATTILA PÁL ${ }^{2}$ \& \\ RÓBERT GÁSPÁR ${ }^{1}$
}

${ }^{1}$ Department of Pharmacodynamics and Biopharmacy, Faculty of Pharmacy, University of Szeged, Szeged, Hungary, and ${ }^{2}$ Department of Obstetrics and Gynecology, Albert Szent-Györgyi Clinical Center, Faculty of General Medicine, University of Szeged, Szeged, Hungary

\begin{abstract}
Objective. We investigated how progesterone and salmeterol modify the effect of nifedipine in an in vivo preterm birth model in rats, and how terbutaline and nifedipine modify the contractions of the isolated human myometrium. Design. Experimental animal and human myometrial studies. Sample. Twenty-four female Sprague-Dawley rats and 13 human uterine tissues sampled from cesarean section. Methods. Preterm birth was induced in Sprague-Dawley rats with a combination of mifepristone and prostaglandin- $\mathrm{E}_{2}$. The animals were treated with nifedipine or its combination with salmeterol and progesterone. Additionally, isolated human myometrial strips from cesarean sections were stimulated with oxytocin, and the inhibitory effects of nifedipine and terbutaline were studied. Results. Nifedipine delayed the preterm delivery in the rats, but its effect was tripled by the addition of $\beta_{2}$-mimetics, or abolished after progesterone pretreatment. Synergism was observed in the relaxing effects of nifedipine and terbutaline on the isolated human myometrium. Conclusion. The action of nifedipine in delaying labor is impeded by progesterone. A combination of nifedipine and $\beta_{2}$-agonists should be considered for the treatment or prevention of preterm birth.
\end{abstract}

Key words: $\beta_{2}$-Mimetics, nifedipine, preterm, progesterone

\section{Introduction}

Preterm birth is the major cause of perinatal mortality and morbidity in the developed world. With a view to decreasing the potential maternal and fetal adverse events and improving the perinatal outcome, there is growing interest in experimental studies of the possible use of different tocolytic combinations $(1,2)$.

The most important factor governing the force of myometrial contractility is dependent not only on $\mathrm{Ca}^{2+}$ entry but also on the propagation of electrical signals over the uterus to recruit additional cells. In the myometrium, the membrane potential is the major factor influencing the entry of $\mathrm{Ca}^{2+}$ into the cells via the L-type $\mathrm{Ca}^{2+}$ channels. Dihydropyridine antagonists such as nifedipine exert their effects by binding to L-type channels; they act by abolishing transmembrane calcium influx, and impede the increase in intracellular $\mathrm{Ca}^{2+}$ necessary for activation of the contractile proteins. Among the $\mathrm{Ca}^{2+}$ entry blockers, the dihydropyridines are the most potent and selective inhibitors of uterine tension development, and have been used as tocolytics to prevent preterm labor for more than 20 years (3-5).

The activity of L-type $\mathrm{Ca}^{2+}$ channels is regulated by several factors (6). $\beta$-Adrenergic stimulants are known to produce smooth muscle cell relaxation by raising the intracellular level of cyclic AMP, which

Correspondence: Róbert Gáspár, Department of Pharmacodynamics and Biopharmacy, Faculty of Pharmacy, University of Szeged, P.O. Box 121,

Szeged H-6701, Hungary. E-mail: gaspar@pharm.u-szeged.hu

(Received 2 March 2010; accepted 1 fuly 2010)

ISSN 0001-6349 print/ISSN 1600-0412 online (C) 2010 Informa Healthcare

DOI: $10.3109 / 00016349.2010 .512064$ 
activates protein kinase $\mathrm{A}$. This activated form leads to phosphorylation of the $\mathrm{Ca}^{2+}$ channels. This mechanism in the heart muscle (7) might be similar to that in the pregnant myometrium. Investigation of the effects of combination of $\beta_{2}$-agonists and $\mathrm{Ca}^{2+}$ channel blockers in the isolated trachea has demonstrated that both isradipine and nifedipine potentiated the relaxant action of terbutaline and salmeterol, respectively (8). We earlier reported (9) that the addition of a $\beta_{2}$-agonist to a $\mathrm{Ca}^{2+}$ channel blocker enhanced the effect of the $\mathrm{Ca}^{2+}$ antagonist on the isolated pregnant rat myometrium, although the extent of potentiation depended on the sequence of administration of the two compounds. The efficacy of this combination has neither been investigated in vivo nor tested in human uterine tissue.

Another factor which regulates the L-type $\mathrm{Ca}^{2+}$ channel is the progesterone/estrogen ratio. Helguera et al. (10) established that the uterine smooth muscle possesses $\alpha_{1 \mathrm{C}-\text { long }}$ and $\alpha_{1 \mathrm{C}-\text { short }} \mathrm{Ca}^{2+}$ channels isoforms. Progesterone favors the expression of the long form, in the presence of which the channel has lower activity. We found (9) that progesterone pretreatment decreased the inhibitory effect of nifedipine in the isolated rat myometrium, but there have been no studies to confirm this in vivo.

Our aims in the present study were to learn whether the administration of nifedipine or a nifedipine- $\beta_{2^{-}}$ agonist combination can delay preterm birth, whether this latter combination influences the contractions of the isolated human myometrium, and whether progesterone treatment decreases the effects of nifedipine in hormone-induced preterm delivery in rats in vivo.

\section{Material and methods}

\section{Animal studies}

The animals were treated in accordance with the European Communities Council Directives (86/609/ ECC) and the Hungarian Act for the Protection of Animals in Research (XXVIII.tv.32.§). All experiments involving animal subjects were carried out with the approval of the Hungarian Ethical Committee for Animal Research (registration number: IV/ 1758-2/2008). Sprague-Dawley rats (Charles River Laboratories, Hungary) were kept at $22 \pm 3^{\circ} \mathrm{C}$; the relative humidity was $30-70 \%$ and the light/dark cycle was 12 hours/12 hours. They were maintained on a standard rodent pellet diet (Charles River Laboratories), with tap water available ad libidum.

Mature female (180-200 g) and male (240-260 g) Sprague-Dawley rats were mated in a special mating cage. Vaginal smears were taken from the female rats and a sperm search was performed under a microscope at a magnification of $\times 1200$. If the smear proved positive, the female rats were separated and were regarded as first-day pregnant animals.

Preterm labor was induced according to Rechberger et al. (11). Briefly, the animals were treated with mifepristone ( $3 \mathrm{mg}$ per $0.1 \mathrm{ml}$ ) (donated by Richter Gedeon NyRt, Budapest, Hungary) and prostaglandin- $\mathrm{E}_{2} \quad\left(\mathrm{PGE}_{2} ; 0.5 \mathrm{mg} / \mathrm{animal}\right)$ (SigmaAldrich, Budapest, Hungary) on day 19 of pregnancy, considered that the duration of pregnancy is 22 days in the rat. Mifepristone was suspended in olive oil (Sigma-Aldrich, Budapest, Hungary) and administered as a subcutaneous injection at 9:00 am. At 4:00 pm, $\mathrm{PGE}_{2}$ was applied intravaginally. The delivery time of the first fetus was noted as the duration in hours from the time of mifepristone administration.

Nifedipine (Sigma-Aldrich, Budapest, Hungary) was dissolved in a 6:6:4 polyethylene glycol (SigmaAldrich, Budapest, Hungary), ethanol (Sigma-Aldrich, Budapest, Hungary) and physiologic saline mixture. Salmeterol xinafoate (Sigma-Aldrich, Budapest, Hungary) was dissolved in a 1:1 methanol (SigmaAldrich, Budapest, Hungary) and water mixture. Alzet osmotic pumps (model 2ml1; DURECT Corp., Cupertino, CA) were loaded with nifedipine, salmeterol xinofoate solution or vehicle. In the combination studies, two separate osmotic pumps were inserted subcutaneously into the back skin of the rats on day 16 or 18 of pregnancy (which may correlate to gestation weeks 30-35 in humans) under isoflurane anesthesia (Burton's narcotic apparatus). The dose of nifedipine was $3.89 \mathrm{mg} /$ day per animal and that of salmeterol xinofoate was $0.13 \mathrm{mg} /$ day per animal.

The progesterone (Sigma-Aldrich, Budapest, Hungary) treatment was started on day 15 of pregnancy. Progesterone was dissolved in corn oil (Sigma-Aldrich, Budapest, Hungary) and injected subcutaneously daily until delivery (day 19 or 20) in a dose of $0.5 \mathrm{mg} / 0.1 \mathrm{ml}$.

Group A was the control group, while group B was treated with vehicle, group $\mathrm{C}$ with nifedipine, group $\mathrm{D}$ with the nifedipine-salmeterol combination and group $\mathrm{E}$ with the nifedipine-progesterone combination. There were eight rats in each group.

\section{Human myometrial studies}

Biopsy specimens of human myometrial tissue were obtained at cesarean section in the third trimester of pregnancy. Uterine smooth muscle tissue samples were collected at 37-40 weeks of gestation from 13 women who were underwent cesarean delivery 
because of fetal distress, growth restriction, a previous cesarean delivery, breech presentation, or suspected cephalopelvic disproportion. None of the women was treated with any tocolytic agent. The parity of the women varied from 0 to 3 , and their mean age was 29.7 years, range $26-37$ years. In all cases, the operation was performed under spinal anesthesia. The Ethical Committee of Albert Szent-Györgyi Clinical Center approved the clinical protocol for the use of human tissue from fully informed and consenting women (registration number: 114/2009). Each tissue sample $(10 \times 10 \times 20 \mathrm{~mm})$ was obtained from the upper edge of a lower-segment transverse incision, after delivery of the child, but before oxytocin was given to the mother. Tissues were stored in KrebsHenseleit solution at $4^{\circ} \mathrm{C}$, and were used within 12 hours of collection.

Longitudinal myometrial strips (measuring approximately $3 \times 5 \times 10 \mathrm{~mm}$ ) were mounted vertically in an organ bath containing $10 \mathrm{ml}$ Krebs-Henseleit (composition: $118 \mathrm{mM}$ sodium chloride, $5 \mathrm{mM}$ potassium chloride, $2 \mathrm{mM}$ calcium chloride, $0.5 \mathrm{mM}$ magnesium sulfate, $1 \mathrm{mM}$ potassium sulfate, $25 \mathrm{mM}$ sodium bicarbonate, $10 \mathrm{mM}$ glucose; $\mathrm{pH}$ 7.4) solution. The organ bath was maintained at $37^{\circ} \mathrm{C}$ and carbogen $\left(95 \% \mathrm{O}_{2}+5 \% \mathrm{CO}_{2}\right)$ was bubbled through it. After mounting, the rings were equilibrated for $\sim 2$ hours before experiments were undertaken, with a solution change every 15 minutes.

We searched for the optimum initial tension. The best response appeared with a pretension of $2-3 \mathrm{~g}$. In order to maintain adequate tension even after higher spontaneous relaxation, the initial tension of the preparation was set to $\sim 3.00 \mathrm{~g}$, which was relaxed to $\sim 1.5 \mathrm{~g}$ at the end of equilibration.

The tension of the myometrial rings was measured with an isometric force transducer (SG-02; Experimetria Ltd., Budapest, Hungary) and recorded with a SPEL Advanced ISOSYS Data Acquisition System (Experimetria Ltd., Budapest, Hungary).

The first responses of the strips to $10^{-6} \mathrm{M}$ oxytocin were analyzed at the beginning of the experiments. No differences were found between contractility of the myometrial strips suggesting that pharmacological sensitivities of the samples were very similar. In each experiment, an untreated control preparation was included to measure the relaxation caused by spontaneous relaxation of the tissues. After eliciting contractions with $10^{-6} \mathrm{M}$ oxytocin, non-cumulative dose-response curves were constructed for each experiment with nifedipine $\left(10^{-11}-10^{-5} \mathrm{M}\right)$ and terbutaline (Sigma-Aldrich, Budapest, Hungary) $\left(10^{-7} \mathrm{M}\right)$ or terbutaline $\left(10^{-11}-10^{-5} \mathrm{M}\right)$ and nifedipine $\left(10^{-7} \mathrm{M}\right)$. Drugs were used from stock solutions and stored at $-20^{\circ} \mathrm{C}$.

\section{Statistical analysis}

In the animal studies, statistical analyses were carried out through the analysis of Dunnett's Multiple Comparison Test.

In the human myometrial studies, concentrationresponse curves were fitted, and area under curves (AUCs) were evaluated and analyzed with the Prism 4.0 (Graphpad Software Inc., San Diego, CA, USA) computer program. In all experiments an untreated control preparation was included to ensure that no spontaneous decrease in contractile activity occurred during the experimental period. The maximal inhibitory effect $\left(\mathrm{E}_{\mathrm{max}}\right)$ and $\mathrm{EC}_{50}$ values in the curves obtained with the combinations were calculated. For statistical evaluations, data were analyzed by the unpaired $t$-test.

\section{Results}

In vivo studies

In group A (control), preterm labor occurred within 24 hours after mifepristone treatment, at about 9:00 am on pregnancy day 20. The vehicle (group B) did not alter the time of delivery relative to that in group A.

Nifedipine (group C) treatment started on pregnancy day 16 was effective in delaying the hormoneinduced preterm delivery by 6.6 hours. In group D (nifedipine-salmeterol combination), the treatment was extremely effective; preterm birth was delayed by $\sim 24$ hours as compared with group A (Figure 1).

When started on day 18 of pregnancy (Figure 2), nifedipine treatment (group C) was not effective. By contrast, in group D (combination therapy) the treatment was effective; labor was delayed by $\sim 25$ hours. The difference in efficacy between groups $\mathrm{C}$ and $\mathrm{D}$ was most expressed for the treatment started on day 18.

With the nifedipine-progesterone combination (Figure 3), the progesterone pretreatment (group E) abolished the effect of nifedipine (group C).

\section{Organ bath studies}

The $10^{-6} \mathrm{M}$ oxytocin-stimulated human uterine contractions were inhibited concentration-dependently by nifedipine and terbutaline in the range $10^{-11}-10^{-5} \mathrm{M}$ (Figure 4A,B). The addition of $10^{-7} \mathrm{M}$ terbutaline to nifedipine did not alter the $\mathrm{E}_{\max }$ of nifedipine, but increased $\mathrm{EC}_{50}$ from $1.8 \times 10^{-8} \mathrm{M}$ to $1.5 \times 10^{-6} \mathrm{M}$ $(p<0.05)$ (Figure 4A). The addition of $10^{-7} \mathrm{M}$ 


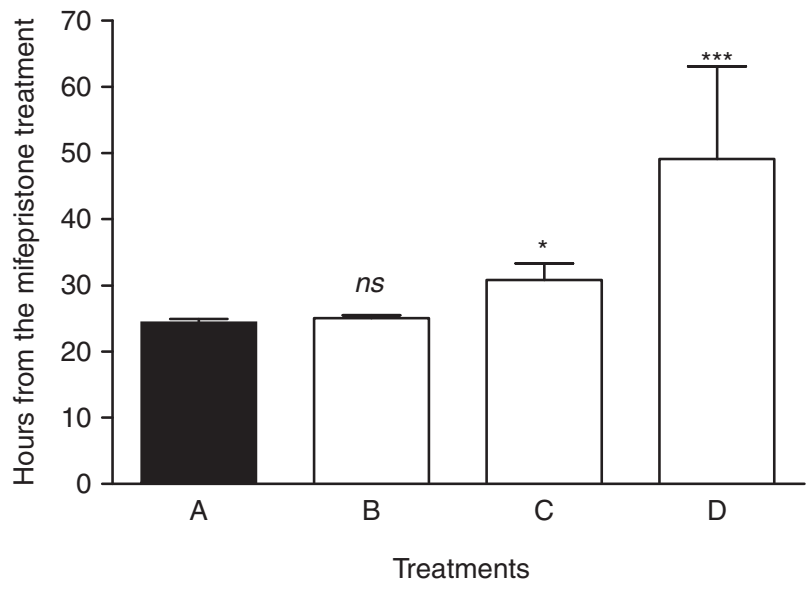

Figure 1. The effects of treatment with nifedipine $(3.89 \mathrm{mg} /$ day $)$ or the nifedipine-salmeterol combination on hormone-induced preterm delivery in the rat ( $n=8$ for each group). Treatment was started on gestation day 16. A: control group; B: vehicle-treated (PEG400:ethanol:physiological salt solution $=6: 6: 4+$ methanol: water $=1: 1$ in osmotic minipump); C: nifedipine-treated; D: nifedipine-salmeterol combination-treated animals. The bar graphs show means $\pm \mathrm{SD}$. The effects were compared with the results on group A. $n s$, not significant. ${ }^{\star} p<0.05$; ${ }^{\star \star \star} p<0.001$. The difference in efficacy between the treatments in groups $\mathrm{C}$ and $\mathrm{D}$ was significant $(p<0.001)$.

nifedipine to terbutaline increased the $\mathrm{E}_{\max }$ of terbutaline (Figure 4B), from 60.8 to $76.8 \%(p<0.01)$ but $\mathrm{EC}_{50}$ was not changed. Interestingly, nifedipine was able to enhance the relaxing effect of terbutaline to a significant level even at the concentration of $10^{-11} \mathrm{M}$.

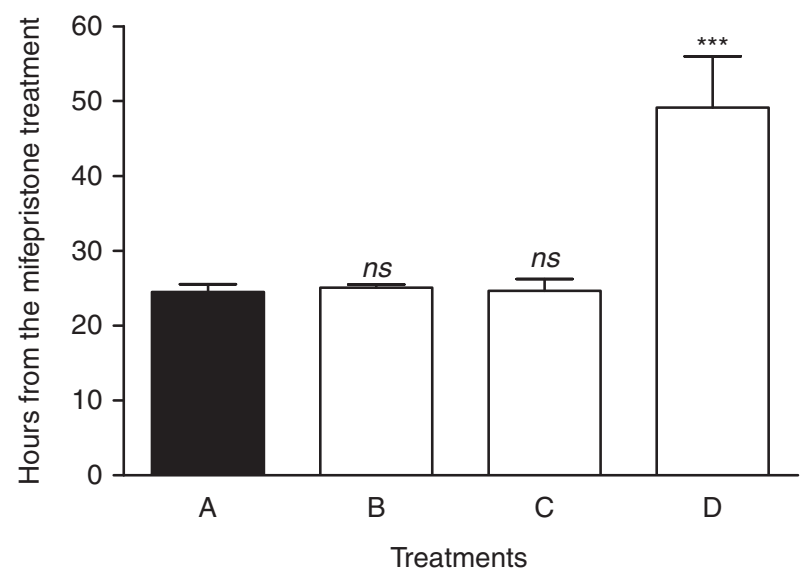

Figure 2. The effects of treatment with nifedipine $(3.89 \mathrm{mg} /$ day $)$ or the nifedipine-salmeterol combination on hormone-induced preterm delivery in the rat ( $n=8$ for each group). Treatment was started on gestation day 18. A: control group; B: vehicletreated (PEG400:ethanol:physiological salt solution $=6: 6: 4+$ methanol: water $=1: 1$ in osmotic minipump); C: nifedipine-treated; D: nifedipine-salmeterol combination-treated animals. The bar graphs show means $\pm \mathrm{SD}$. The effects were compared with the results on group A. $n s$, not significant. ${ }^{\star \star \star} p<0.001$. The difference in efficacy between the treatments in group $\mathrm{C}$ and $\mathrm{D}$ was significant $(p<0.001)$.

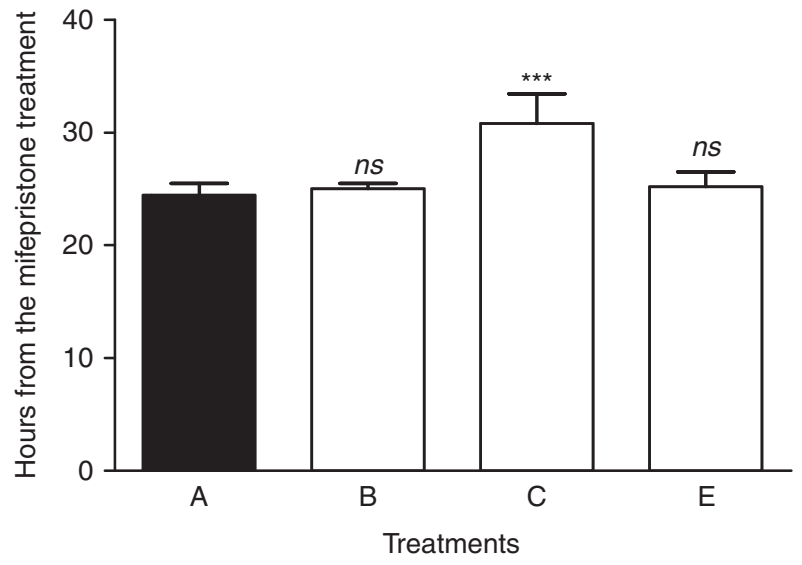

Figure 3. The effects of treatment with nifedipine $(3.89 \mathrm{mg} /$ day) or the nifedipine-progesterone combination on hormone-induced preterm delivery in the rat ( $n=8$ for each group). Treatments were started on gestation day 16. A: control group; B: vehicletreated (PEG400:ethanol:physiological salt solution $=6: 6: 4$ in osmotic minipump + corn oil s.c.); C: nifedipine-treated; $\mathrm{D}$ : nifedipine-progesterone combination-treated animals. The bar graphs show means \pm SD. The effects were compared with the results on group A. $n s$, not significant. ${ }^{\star \star \star} p<0.001$. The difference in efficacy between the treatments in group C and D was significant $(p<0.001)$.

\section{Discussion}

Combinations of different uterine relaxing agents should be considered as a possibility to enhance the efficacy of tocolytic therapy. The effect of combined salmeterol-gestagen treatment in hormone-induced preterm delivery in rats in vivo was investigated earlier (2): salmeterol treatment started on pregnancy day 16 delayed preterm birth by 2.8 hours and the salmeterolprogesterone combination caused a 4.5 -hour delay.

Those results led us to test the efficacy of nifedipinesalmeterol and nifedipine-progesterone combination treatment in hormone-induced preterm delivery in rat in vivo. Preterm delivery was induced by the deprivation of progesterone using progesterone antagonist combined with prostaglandin $\mathrm{E}_{2}$ to accelerate cervical ripening on pregnancy day 19 . At this stage of pregnancy the function of corpus luteum declines which is mainly attributed to the luteolytic effect of prostaglandin $F_{2 \alpha}$ (12). It is also known that progesterone induces the metabolism of prostaglandins, thus substitution of progesterone is anticipated to improve relaxation response in late-pregnant rat uterus (13).

We used the same in vivo salmeterol dose as it was effective in delaying preterm birth, and the progesterone dose that had increased the effect of salmeterol. The in vivo dose for the tocolytic effect was calculated by using the pharmacokinetic parameters reported for nifedipine in pregnant rats by Downing and 


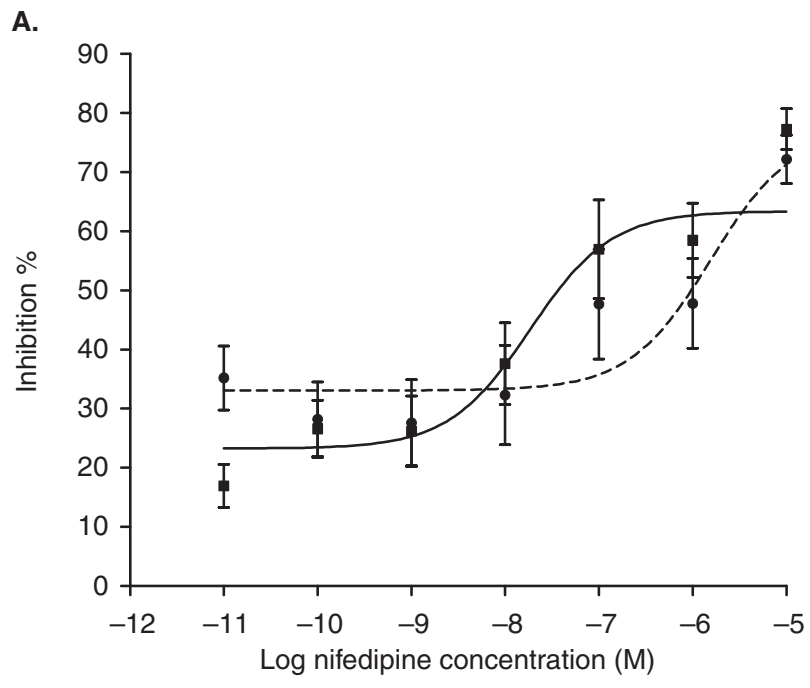

B.

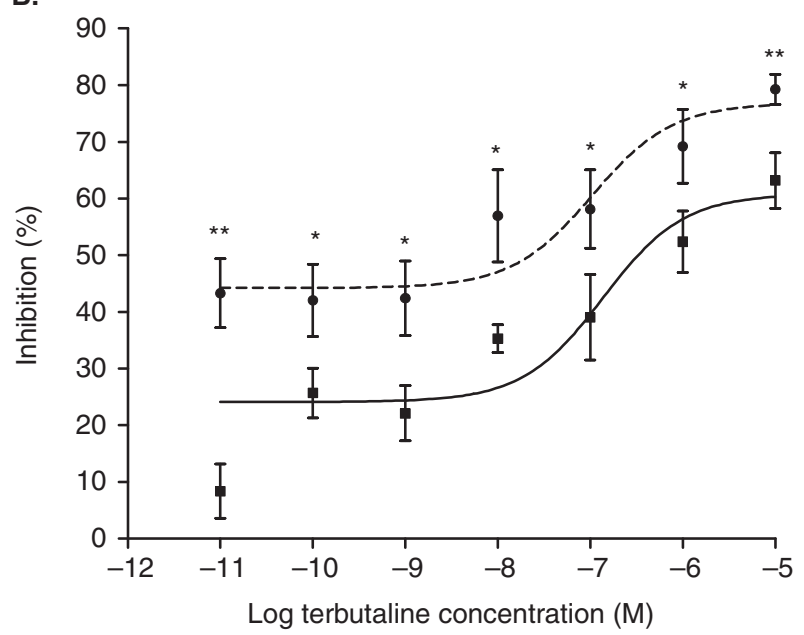

Figure 4. The effects of treatment with the nifedipine-terbutaline combination on oxytocin-evoked human myometrial contractions in vitro. A: ( $)$ nifedipine $\left(10^{-11}-10^{-5} \mathrm{M}\right) ;(\bullet)$ terbutaline $\left(10^{-7} \mathrm{M}\right)+$ nifedipine $\left(10^{-11}-10^{-5} \mathrm{M}\right)$. B: (泊) terbutaline $\left(10^{-11}-10^{-5} \mathrm{M}\right)$; $(\bullet)$ nifedipine $\left(10^{-7} \mathrm{M}\right)+$ terbutaline $\left(10^{-11}-10^{-5} \mathrm{M}\right) .{ }^{\star} p<0.05$; $\star \star p<0.01$.

Hollingsworth (14). We planned the administration of a dose regimen via osmotic pumps which provided a plasma nifedipine concentration of $\sim 1.5 \mu \mathrm{g} / \mathrm{ml}$ (estimated). Downing et al. concluded that this plasma level of the drug did not cause significant changes in heart rate or blood pressure, but elicited a well-defined uterusrelaxing effect. We found that the treatment with nifedipine alone started on pregnancy day 16 was more effective in delaying delivery than salmeterol treatment alone (in the earlier study) (2). Similarly, the nifedipinesalmeterol combination also had a greater effect than the salmeterol-gestagen combination (2).

The short-term effects of nifedipine and its combination with salmeterol were also tested in our experiments. Nifedipine treatment started on day 18 did not delay labor, but the nifedipine-salmeterol combination was as effective as the combination started on the pregnancy day 16 . The ability of nifedipine to delay labor was tripled by its combination with the $\beta_{2}$-agonist.

In vivo progesterone pretreatment was earlier demonstrated to worsen the relaxing effect of nifedipine in vitro (9). Progesterone pretreatment also abolished the ability of nifedipine to delay labor in hormoneinduced preterm delivery in rats in vivo. These results correlate with the hypothesis that progesterone decreases the activity of the L-type $\mathrm{Ca}^{2+}$ channels (10).

In previous study (9), we demonstrated synergism in the uterus-relaxing effects of nifedipine and the $\beta_{2^{-}}$ agonist terbutaline in the isolated rat myometrium, although the extent of the potentiation depended on the sequence of administration of the two compounds. When terbutaline was added first in a single dose, synergism was observed in $\mathrm{EC}_{50}$, but the $\mathrm{E}_{\max }$ of nifedipine was lower. When nifedipine was administered first, the relaxing effect of terbutaline was obviously stronger. The entry of $\mathrm{Ca}^{2+}$ into the cells through the voltage-gated $\mathrm{Ca}^{2+}$ channels is one of the crucial factors in the generation of smooth muscle contraction. $\beta_{2}$-Agonists activate the L-type $\mathrm{Ca}^{2+}$ channels and decrease the $\mathrm{E}_{\max }$ of nifedipine. In the opposite case, when nifedipine is administered first, the L-type $\mathrm{Ca}^{2+}$ channels are blocked; hence, terbutaline cannot activate them.

However, our results contrast with the findings of Downing and Hollingsworth (14). They found that nifedipine displayed more potent myometrial inhibitory effects in pseudopregnant rats treated with high doses of progesterone than in non-pregnant rats. Our results confirmed the reduced uterus-relaxing effect of nifedipine followed by gestagen treatment both in vitro and in vivo; hence, we suppose that the discrepancy in the quality of nifedipine-progesterone interaction might be explained by the dissimilarity of experimental animals (pseudo- and non-pregnant rats vs. pregnant rats).

Synergism between nifedipine and the $\beta_{2}$-agonist terbutaline was also investigated on human myometrium tissue, which revealed that both nifedipine and terbutaline inhibit the oxytocin-induced myometrial contractions dose-dependently. When terbutaline was added first, it decreased the $\mathrm{EC}_{50}$ of nifedipine (the nifedipine curve was shifted to the right), although it did not alter the $\mathrm{E}_{\max }$ of nifedipine. In the opposite case, nifedipine administered first increased the relaxing effect of terbutaline even in very low concentration, although there was no difference in $\mathrm{EC}_{50}$. The results suggest a parallelism between the human situation and that in the rat myometrium.

The question arises as to whether the drug interactions observed between nifedipine and the 
$\beta_{2}$-adrenergic receptor agonists in vitro apply under in vivo circumstances. In our in vivo study, two osmotic pumps were implanted subcutaneously in the rat and the administration of the two agents was simultaneous and continuous. The results suggested that the parallel administration of the two compounds may lead to a similar benefit as that of nifedipine-potentiated terbutaline treatment.

A weakness of this study is that the experiments do not provide data relating to the prompt effect of the drugs in the onset of hormone-induced preterm birth, but the investigation of this effect is almost impossible in rats. The first visual sign of the onset of labor is vaginal bleeding. From this time on, at most only $10-15$ minutes is available until the delivery of the first fetus. This short period is not sufficient for the absorption of drugs administered. On the other hand, intravenous drug administration to delivering rats would be very difficult and might well cause severe stress for the animal, altering the delivery process. Despite this weakness, our study reports the first attempt to delay anti-gestagen-prostaglandin-induced preterm birth in vivo with a $\mathrm{Ca}^{2+}$ antagonist or a $\mathrm{Ca}^{2+}$ antagonist-gestagen combination. Additionally, the effects of $\mathrm{Ca}^{2+}$ antagonist- $\beta_{2}$-agonist combinations on the pregnant human myometrium were proved.

\section{Conclusion}

Progesterone pretreatment abolished the ability of nifedipine to delay labor in hormone-induced preterm delivery in rats. The effect of nifedipine in tocolytic therapy might be intensified through combination with $\beta_{2}$-adrenergic agonists. However, the administration of $\beta_{2}$-adrenergic agonists cannot precede that of nifedipine.

\section{Acknowledgement}

This work was supported by a Hungarian OTKA Research Grant (K62707).

Declaration of interest: The authors report no conflicts of interest. The authors alone are responsible for the content and writing of the paper.

\section{References}

1. Kim A, Shim JY. Emerging tocolytics for maintenance therapy of preterm labour: oxytocin antagonists and calcium channels blockers. Br J Pharmacol. 2006;113(Suppl 3):113-15.

2. Gálik M, Gáspár R, Kolarovszki-Sipiczki Z, Falkay G. Gestagen treatment enhances the tocolytic effect of salmeterol in hormone-induced preterm labor in the rat in vivo. Am J Obstet Gynaecol. 2008;198:319.e1-5.

3. Oei SG. Calcium channel blockers for tocolysis: a review of their role and safety following reports of serious adverse events. Eur J Obstet Gynaecol. 2006;126:137-45.

4. Longo $M$, Jain V, Vedernikov YP, Hankins GDV, Garfield RE, Saade GR. Effects of L-type $\mathrm{Ca}^{+}$-channel blockade, $\mathrm{K}^{+} \mathrm{ATP}$-channel opening and nitric oxide on human uterine contractility in relation to gestational age and labor. Mol Hum Reprod. 2003;9:159-64.

5. Wray S, Jones K, Kupittayanant S, Li Y, Matthew A, Monir-Bisthty E, et al. Calcium signaling and uterine contractility. J Soc Gynecol Investig. 2003;10:252-64.

6. Kobayashi T, Yamada Y, Fukao M, Tsutsuura M, Tohse N. Regulation of Cav1.2 current: interaction with intracellular molecules. J Pharmacol Sci. 2007;103:347-53.

7. Kamp TJ, Hell JW. Regulation of cardiac L-type calcium channels by protein kinase $\mathrm{A}$ and protein kinase C. Circ Res. 2000;87:1095-102.

8. Thirstrup S, Nielsen-Kudsk F, Dahl F. In vitro studies on the interactions of $\beta_{2}$-adrenoreceptor agonists, methylxanthenes, $\mathrm{Ca} 2^{+}$-channel blockers, $\mathrm{K}^{+}$-channel openers and other airway smooth muscle relaxants in isolated guinea-pig trachea. Eur J Pharmacol. 1997;326:191-200.

9. Hajagos-Tóth J, Falkay G, Gáspár R. Modification of the effect of nifedipine in the pregnant rat myometrium: the influence of progesterone and terbutaline. Life Sci. 2009; 85:568-72.

10. Helguera $G$, Olcese $R$, Song $M$, Toro L, Stefani $E$. Tissue-specific regulation of $\mathrm{Ca}_{2}{ }^{+}$channel protein expression by sex hormones. Biochim Biophys Acta. 2002;1569: 59-66.

11. Rechberger $\mathrm{T}$, Abramson SR, Woessner JF Jr. Onapristone and prostaglandin E2 induction of delivery in the rat in late pregnancy: a model for the analysis of cervical softening. Am J Obstet Gynecol. 1996;175:719-23.

12. Hernandez F, Peluffo MC, Bas D, Stouffer RL, Tesone M. Local effects of the sphingosine 1-phosphate on prostaglandin F2alpha-induced luteolysis in the pregnant rat. Mol Reprod Dev. 2009;76(12):1153-64

13. Farina M, Ribeiro ML, Weissmann C, Estevez A, Billi S, Vercelli C, et al. Biosynthesis and catabolism of prostaglandin F2alpha (PGF2alpha) are controlled by progesterone in the rat uterus during pregnancy. J Steroid Biochem Mol Biol. 2004; 91(4-5):211-18.

14. Downing SJ, Hollingsworth $M$. Nifedipine kinetics in the rat and relationship between its serum concentrations and uterine and cardiovascular effects. Br J Pharmacol. 1998;95: 23-32. 